\title{
Rethinking environmental justice: capability building, public knowledge and the struggle against traffic-related air pollution
}

\author{
Maarten Loopmans*, Linde Smits** and Anneleen Kenis*** \\ * corresponding author, Division of Geography and Tourism, Department of Earth and Environmental \\ Sciences, University of Leuven, Celestijnenlaan 200E, 3001 Leuven, Belgium. Email: \\ maarten.loopmans@kuleuven.be \\ **independent researcher, email: linde.smits@outlook.be \\ ${ }^{* * *}$ Division of Geography and Tourism, Department of Earth and Environmental Sciences, University of \\ Leuven, Celestijnenlaan 200E, 3001 Leuven, Belgium. Email: $\underline{\text { Anneleen.Kenis@kuleuven.be }}$
}

Accepted version, please cite as: Loopmans, M., Smits, L. \& A. Kenis (2021) Rethinking Environmental Justice: capability building, public knowledge and the struggle against traffic-related air pollution, Environment and Planning C: Politics and Space.

Abstract

For more than a decade, a broad social movement has organized significant opposition to the expansion of the Antwerp ring road. By linking the very mobile, intangible and unplaceable problem of trafficrelated air pollution to the highly local, concrete, immobile issue of the highway, they succeeded in creating the largest mobilization against air pollution ever in Belgium. A distributive justice discourse which portrayed Antwerp residents as being unfairly affected has played a crucial role in this endeavor. At the same time, the movement has struggled to involve and represent those who will be most affected by the ring road extension. Low income and ethnic minority residents living close to the ring road are strikingly absent from the movements' ranks and tend to be silenced in its discourse. In this paper, we scrutinize this disparity between the social composition of the most affected areas and the social composition of the movement dealing with the issue, and reflect on the movement's practices of knowledge production and dissemination from an environmental justice perspective. We highlight the need for expanding environmental justice beyond a merely distributive approach and argue that environmental justice movements need to see knowledge dissemination and public pedagogy as more than just a mobilizing strategy. Without pursuing equity in the distribution of networks, capabilities and knowledge, enhancing the possibilities of those who are most affected to the develop their own strategies, environmental justice is difficult to realize.

\section{Introduction: traffic infrastructure expansion, air pollution and environmental justice}

The environmental injustice of air pollution has mainly been addressed from a distributive perspective. However, air pollution not only entails huge distributional inequalities, but also complex procedural, recognition and capabilities entanglements (Taylor, 2014; Schlosberg, 2013). As Walker argued already in 2009, we need to 'promote a move beyond the distributional in geographical research towards a fuller and more integrated understanding of environmental justice and its spatial characteristics' (p.615-616). 
Based on a decade of scholarly and activist engagement with air pollution in Antwerp (Belgium), this paper discusses how environmental movements in Antwerp have struggled to address social justice issues in their mobilizations. Since 2005, local activists have persistently resisted the expansion of the Antwerp Ring road, which passes through the most densely inhabited areas of the city. Air pollution has played a crucial role in their mobilization discourses and strategies. The movement has successfully engaged an impressively wide public with the issue, moving back and forth between the topic of the highly local, concrete, immobile issue of the highway and the more mobile, intangible and unplaceable subject of traffic-related air pollution. At the same time, the social basis of the movement continues to be primarily white and middle-class, and struggles to represent those who will be most affected by the ring road extension. As we have shown in a previous study (Loopmans et al., 2017), lower income and ethnic minority groups are overrepresented in the areas closest to the ring road. In this paper, we aim to understand this disparity between the social composition of the most-affected areas and the social composition of the movement dealing with the issue, and critically reflect on how particular knowledge claims and mobilization strategies influence power dynamics.

In what follows, we first discuss the literature on distributional justice and air pollution, calling to put additional dimensions of justice more centrally on the research agenda. Subsequently, we shortly discuss the history of air pollution struggles in Antwerp and introduce our research design. In the next section, we first present the perspective of the action groups, in order to then turn to the perspective of those who seem to be forgotten - as active agents - in the struggle for clean air. Bringing these two perspectives together, we conclude that expanding environmental justice beyond the distributive is key and requires the extension of networks, capabilities and knowledge.

\section{Beyond a just distribution of air}

Environmental justice is addressed from four complementary perspectives: distributive and procedural justice, recognition and the capabilities approach (Walker, 2012; Hollifield, Chakraborty \& Walker, 2017; Schlosberg, 2007). Most studies focus on a distributive analysis of air pollution, distinguishing between exposure, vulnerability and responsibility. Exposure to air pollution both at the level of the residence (Tenailleau et al., 2015) and at the level of the individual (Maantay, 2007; Nyarku et al., 2018) is conditioned by socio-economic structures. The groups with lowest socio-economic status are generally shown to be most exposed to air pollution, independent of the scale of measurement (Maroko, 2012; Gray et al., 2013; Rose-Pérez, 2015; Knibbs \& Barnett, 2015; Verbeek, 2019). Recently, studies have also shown an effect of ethnic background even after control for deprivation (Fecht et al., 2016) whereas others reveal more complex and sometimes even contradictory results. Some find a higher exposure of high-income groups or a mixed pattern (Fecht et al., 2015; Da Schio et al., 2018), and call for a contextsensitive analysis.

Vulnerability has received ample attention too. Early studies mainly refer to physical health effects. More recently, the concept of vulnerability has come to encompass the lack of knowledge of or access to health care or individual protective measures (e.g. face masks in the case of air pollution) and is regarded as a wider, multifaceted structural lack of ability to adapt and protect oneself from the effects of air pollution (e.g. Makri \& Stilianakis, 2008; Maroko, 2012). Consequently, apart from physically 
vulnerable age groups, vulnerability is generally considered to be higher amongst lower income groups and ethnic minorities (Gilbert \& Chakraborty, 2011; Hajat, Hsia \& O'Neill, 2015).

Finally, studies about responsibility equally emphasize differences amongst socio-economic groups, in particular in the context of a rising share of traffic as a source of air pollution in urban areas (Davoudi \& Brooks, 2014, Graham, 2015). This is not irrelevant as traffic is considered largely responsible for intraurban variations (Buzzelli, 2008). Differences in car possession and exposure to its exhaust gases can be considered a source of injustice (Pearce et al., 2010). Studies reveal how inequalities in exposure and car use are related to the socio-economic structuring of the urban region, with middle class car commuters preferring to live in the periphery of the city whereas poor residents dependent on public transport try to find a place closer to the center (Guerra, 2015; Collins et al, 2015). Recent studies have revealed how higher income families do not only own more cars, but also cars which pollute more per $\mathrm{km}$. They also drive longer distances, compared to lower income car owners (Barnes et al., 2019). In sum, air pollution's distributional justice is a highly complex subject, with diverse geographies of exposure, vulnerability and responsibility intersecting with socio-economic and demographic characteristics (Walker, 2012; Hajat et al, 2015).

Another major strand of environmental justice research focuses on the processes explaining patterns of inequality and injustice. This procedural side of environmental justice has received less attention, even though it is generally recognized as important and inextricably linked to distribution (Schlosberg, 2003; Schlosberg \& Caruthers, 2010; Walker, 2009; 2012). Discussing air pollution from a procedural justice perspective requires the analysis of indirect consequences of systemic processes as much as institutional procedures (Schlosberg, 2013). Analyses typically focus on the housing market (Guerra, 2015), and the way it relegates low incomes groups and ethnic minorities to polluted locations (Taylor, 2014; Germani et al, 2014), or, alternatively, on how new polluting infrastructures, like highways and incinerators, are more frequently constructed in predominantly low income or ethnic minority neighborhoods (Laurian and Funderburg, 2014). Another way of approaching environmental justice is addressing it from the perspectives of recognition and participation (Davoudi \& Brooks, 2014). A recognition perspective implies that certain groups and individuals lack recognition as full citizens whose interests and rights need to be taken into account equally in decision making. Environmental racism, a longstanding focus in environmental justice research, explicitly discusses the effects of misrecognition (Pulido, 1996; Schlosberg, 2013). Recognition also assumes 'parity of participation' in collective decision making affecting environmental conditions (Rose-Pérez, 2015; Kashwan, 2017).

Finally, Schlosberg (2007) and Holland (2008) have introduced the capabilities approach into environmental justice debates to elaborate the connections between distributive and procedural justice. The capability approach to environmental justice emphasizes the importance of just procedures to allow for more equally distributed individual and collective capabilities. Capabilities are seen as 'conditions of human enablement that make it possible for people to achieve things, such as 'being able to have good health' (Holland, 2008, p. 412). Such capabilities also entail an expanded understanding of distributive justice as they do not only include an equitable distribution of environmental goods, but also of knowledge, imagination, social networks, influence etc. (Robeyns, 2003; Holland, 2008). The capabilities 
approach gives a prominent role to pedagogical interventions (Walker, 2006), also from the side of social movements (Schlosberg and Carruthers, 2010).

Air pollution, due to its particular qualities, increases the importance of such pedagogical interventions. Since traffic-related air pollution is largely invisible and is often the implicit and unrecognized externality of decisions about seemingly unrelated facilities such as offices, parking lots, housing... (Da Schio et al., 2018; Kenis and Lievens, 2021; ), parity of information about air pollution's localization and health effects or about a decision's effect on the spatial and social distribution of air quality is important to guarantee equity and equality in participation (Kim et al., 2012; Davoudi \& Brooks, 2014). This includes participation in collective decision-making procedures about air quality distribution, as well as participation in society as knowledgeable individuals. Because of the largely intangible character of traffic-related air pollution, access to information plays a crucial role in raising awareness and concern about air pollution (Peng et al., 2019; Adey, 2013; Bickerstaff \& Walker, 2001), and in increasing people's capabilities (Holland, 2008; Schlosberg and Caruthers, 2010) for individual or collective action to improve their situation. Hence environmental justice praxis includes many examples of 'democratic science' by and with low-income or minority populations on health issues (Corburn, 2005, Sze, 2006; De Lima et al., 2021), particularly in relation to air pollution (Sze \& London, 2008; Van Brussel \& Huyze, 2019).

For these very same reasons, mobilizing against traffic-related air pollution, is a challenging endeavor. As traffic-related air pollution is rarely the direct object of clear, tangible decision making over specific social and physical infrastructures, few occasions are available that could trigger awareness about the effect of such decisions on air quality. Moreover, the intangible and invisible character of many trafficrelated air pollutants as well as the indirect nature of its effects on health make it harder to directly perceive a related danger. The unequal geographies and power relations inscribed in the air are equally hard to read (Bryant, 1998). Since concerns about traffic-related air pollution depend on knowledge about air pollution and its adverse effects (Adey, 2013; Hamersma et al., 2017), knowledge production and dissemination is crucial. Environmental justice movements are well aware of this. But knowledge on air quality and its health effects is not equally distributed either. Young adults, high income and higher educated groups are said to be more aware of and concerned about air pollution's effects (Kim et al., 2012; Peng et al. 2019). Ethnic minority groups, especially recent immigrants with little knowledge of the official language, tend to have less access to information about local air quality and its health effects. Furthermore, for lower income groups, concerns over air pollution might be imbricated with other material concerns over basic necessities (Burningham \& Trush, 2003; Veron, 2006). Kennedy \& Givens (2019), explain lower levels of concern for environmental issues amongst lower income groups with a stronger perception of powerlessness, and Pearson et al. (2018) discuss how a perception of environmental advocacy groups as predominantly white and middle class negatively affects engagement with such groups amongst lower income groups and ethnic or racial minorities. Similarly, knowledge about responsibilities and alternatives (Finkelstein \& Truchot, 2006; Davoudi \& Brooks, 2014; Hamersma et al., 2015), but also experiences of non-recognition in decision making (Hamersma et al., 2017), appear important to perceive air pollution as injustice.

On all these fields, movement organizers face an uphill battle against the obfuscating nature of air pollution itself (Wakefield et al., 2006; Lejeune \& Teller, 2016; Coppens et al., 2018). To politicize air 
pollution and mobilize a population requires considerable discursive work (Pezzulo, 2001;Kenis, 2020) to produce, frame, formulate and disseminate knowledge about air pollution and its uneven geographies. However important such efforts are, they in themselves need to be problematized to move beyond a mere distributive justice perspective (Gibson-Wood \& Wakefield, 2012). How do movements choose to organize participation and knowledge dissemination? Do they succeed in building intersectional solidarity (Loopmans et al., 2020) with the most (information-)deprived groups? Do they increase individuals' capabilities to improve health conditions (Schlosberg \& Caruthers, 2010)? We will discuss these issues in relation to the largest-scale mobilization against air pollution in Belgium, where information dissemination and the strategic mobilization of environmental justice discourses was a key strategy.

\section{Research context and design}

\subsection{Ring road expansion and air pollution protest in Antwerp}

Belgium is one of Europe's most significant air pollution hotspots. In 2000, the average Belgian was said to lose 13,2 months of their life as a result of air pollution, compared to a European average of 8,1 months (Ammann et al., 2005). Still in 2020, residents of Belgium's densely urbanized northern region Flanders are said to lose 14 months of their healthy life as a consequence of PM10 and PM2,5 pollution, and an additional 3 months as a consequence of NO2 (VMM, 2020a). Traffic is one of the most important sources of air pollution, generating $18 \%$ of $\mathrm{PM} 2,5$ and $52 \%$ of NOx (VMM, 2020b). A lack of effective spatial planning, massive sprawl and the fiscal subvention of diesel cars are at the origins of this problem. In particular, the big contribution of traffic to NOx emissions can be related to the prominence of diesel cars in Belgium (Degraeuwe et al., 2016). Fortunately, the share of road transport in PM2,5 and NOx emissions has steadily declined since 2000, largely due to an increased emission efficiency of trucks and cars (VMM, 2020c). Yet in urban areas, the concentration of pollutants due to transport remains high. Antwerp and Brussels are particularly hit, facing high levels of NOx-related mortality in 2015 compared to other European cities (Khomenko et al., 2021). In 2011, Antwerp residents were estimated to lose 2,3 years of their life as a consequence of the combined effect of traffic related air pollution and traffic noise (14,6 months for PM2,5 and PM10 alone)(Lefebvre et al., 2011). Traffic, together with the city's port and residential heating are the main sources of pollution. With $80 \%$ non-local traffic, the ring road cuts through the heart of the city, exposing the most densely populated areas to high air pollution levels. About $2 / 3$ of the city's 550.000 inhabitants live at a distance closer than $1500 \mathrm{~m}$ from the ring road (Van Brusselen et al, 2016).

In 2005, when the regional government announced a new bridge-and-tunnel project, the 'Oosterweelproject', which extends the ring road to the north of the city center, a local committee called 'stRatengeneraal' stood up to resist the project for its negative effects on the city's quality of life. The committee originated from a pre-existing network of grassroots committees in working class neighborhoods with roots in the city's 1970s participation movement (Loopmans, 2008). Developed in a period when urban working class neighborhoods were still largely populated by white, native residents, these committees have struggled in various ways with the challenge to include newly arriving populations, with reactions 
ranging from fierce resistance to immigration to an uncomfortable embrace of the growing local ethnocultural and socio-economic diversity (Beaumont and Loopmans, 2008). stRaten-generaal is an exponent of the latter, having evolved into a network of activists that are largely middle class, well educated and white, but propounding solidarity with fellow residents in their superdiverse neighborhoods in their claims for more public space and public facilities (Claeys, 2013; Loopmans, 2014). To counter the project, it started a legal struggle against procedural errors and the lack of participation in the design process. Three years later, the committee was joined by a new action group called 'Ademloos' (literally 'Breathless'). This action group emphasized public mobilization and built an argument about the health effects of car traffic, arguing that the project would attract extra cars into the city and increase air pollution. They mobilized a network of concerned local physicians and health specialists who would provide them with academic knowledge about the health effects of traffic-related air pollution. Through crowd funding, they were able to pay mobility specialists to develop and analyze an alternative to the government project, proposing to construct the ringway further away from the city center, passing through the port area and less populated, more affluent suburban neighborhoods. Attracting an increasing number of participants throughout the years, stRaten-generaal and Ademloos developed into the first large-scale movement ever to bring traffic-related air pollution under public attention in Belgium. Building on the specialist knowledge of their allies, they started a large information campaign, resulting in a petition for an urban referendum in 2008 (Wolf and Van Dooren, 2017). Collecting signatures from more than $10 \%$ of the Antwerp population, the movement forced the local government to organize a non-binding referendum. The referendum campaign further increased awareness about air pollution as an environmental injustice. 50.000 households put up an Ademloos poster. Information gathered by the movement about air pollution, the government's procedural fraud and eventual alternatives were widely disseminated through social media. At the referendum in 2009, $35 \%$ of the Antwerp population turned up to vote, with $2 / 3$ voting against the Oosterweelproject. The government postponed the project and started a long process of analyzing alternatives, only to announce, five years later, in 2014, the same project again, but replacing the bridge with a tunnel. A new action group, Ringland, surfaced, pursuing the idea that if the project of a new tunnel must continue, then at least the whole inner city ring road could be covered so as to reduce air and noise pollution and create new public space on top of the ring road. Mobilizing urban planning specialist and engineers, they were able to develop a detailed alternative proposal, and through crowd funding, pay independent research institutes to have its health effects compared with the original government proposal. Their proposal would significantly improve air quality, in particular in the poorest neighborhoods of the city, as the tunnel mouths are largely situated in less inhabited or more affluent areas and equipped with the necessary filtering technology (Maiheu et al., 2015). Although a smaller redistributive issue persists as not all tunnel mouths are moved far enough from inhabited area (Van Busselen et al., 2016), the other two movements joined forces with Ringland. In May 2014, they jointly mobilized 12.000 protesters for a march in support of the 'Ringland' proposal (Loopmans, 2014). In 2017, all three action groups collaborated to petition for another referendum in Antwerp, this time collecting over 75.000 signatures. Shortly after, the Flemish government promised to develop a Ringland scenario and the movement organizers were accepted as close participants in the further development of the project, on the condition that the movement's court cases and the petition for a new referendum were withdrawn. Although the Ringland tunnel proposal is still far from guaranteed, the movement 
stopped organizing protest in 2017, but remains active in informing the wider public about air quality and the Ringland-Oosterweel project.

\subsection{Mixed-methods activist research}

The research combined a scholar-activist involvement in the movement during the period 2008-2017 with more formal forms of data gathering and analysis during the period 2013-2018. ${ }^{2}$ The formal part of the research consisted of three phases. The first phase took place in 2013-2014 and consisted of 10 indepth interviews with the most prominent actors involved in Antwerp's air pollution conflict, including representatives of social movements and civil society organizations, policy makers at both the urban and regional level, and public scientists and physicians. The interviews focused on the discursive choices made in mobilizing the population and putting air pollution on the public agenda. All interviews followed a predefined semi-structured interview schedule and took between 1 and 2 hours. The interviews were complemented with a stakeholder-meeting for which 30 key people working on air pollution in Antwerp/Flanders were invited. These stakeholders discussed the topic in 3 thematic working groups. In a second phase, from 2015 to 2017, we produced a number of maps showing the unequal intra-urban variation of air pollution in the city of Antwerp, and its relation to a number of socio-economic indicators like household income and ethnicity (Loopmans et al., 2017). We published these maps and presented them to the movement organizers during a second set of interviews (see below), and, in collaboration with the antiracist 'Movement $X$ ', presented them at a board meeting of the movement network to stimulate awareness about the issue of environmental racism. Both presentations triggered important conversations about the environmental justice goals and strategies of the movement. In a third phase, in 2018, we conducted five focus groups in the different neighborhoods located close to the ring road, with the aim of engaging with neighborhood residents which were least represented in the movement (Smits, 2018). The focus groups were set up in collaboration with a local community based organization, organizing weekly conversation groups for people who wish to improve their fluency in Dutch (Samenlevingsopbouw Antwerpen stad, 2017). 36 local inhabitants participated, all international migrants with a low income but coming from a variety of ethnic backgrounds. The fact that they were not yet fluent in the official language, and often had limited social networks compared to longer term residents made it particularly hard for them to get access to local information about traffic-related air pollution and other local issues. The focus groups were semi-structured, involving both discussion topics, questions and small

\footnotetext{
${ }^{1}$ The scholar-activist engagement of the paper's first author consisted of active involvement in movement building interchanged with periods of more distance. This author was involved in the environmental movements and was also member of the Antwerp chapter of the antiracist organization Movement $\mathrm{X}$ (see https://www.facebook.com/MovementmvX/), from its inception in 2014 till 2017, and helped set up its environmental racism campaign.

${ }^{2}$ All three authors engaged in a part of the empirical data collection. The first author was involved as an activist researcher in the movement and participated in three focus groups and the stakeholder event. The last author conducted the first round of 10 interviews and the stakeholder event. The second author conducted five focus groups and an additional 3 interviews. The respective findings have been put together and discussed on a regular basis whereby the results of the first phase informed the methodological choice for the subsequent steps of the research process.
} 
assignments, such as indicating what they considered the most polluted areas on an Antwerp street map. ${ }^{3}$ Finally, the results of these focus groups and the maps mentioned above were fed back to the representatives of the movements through three additional semi-structured in-depth interviews. In these interviews we focused on the topics of environmental injustice, social deprivation and race. The interviews and focus groups were taped, fully transcribed and coded in NVIVO. Detailed notes were taken at the stakeholder event.

Scholarly activist engagement allowed us not only to understand the general background of the discursive choices made, but also to establish good relations with the people involved and to present them the findings of our first research phases Additionally, it facilitated the reconstruction of events based on occasional and unstructured - notes and access to documents produced and shared by the movements. This helped tying together the findings of the two rounds of interviewing.

\section{Analyzing movement discourses from an environmental justice perspective}

\subsection{Making the invisible visible through spatial representations}

The production and dissemination of knowledge has been a core concern of the movement since the very start. The success and scale of the mobilization is to a large extent related to the successful construction and dissemination of a discourse linking the Oosterweel project with air pollution and its adverse health effects for Antwerp residents. Creating such a discourse was an achievement in itself, in a country where traffic-related air pollution never figured on the political agenda. Even policy makers at the regional level recognized the crucial role of the movement in putting the topic on the map. As one of them replied to a question on awareness raising about air pollution in Flanders:

Actually, to our mind, as an agency, the trigger has been Ademloos and stRaten-generaal who have made Antwerp aware of air quality and health. We were already conscious of the problem, but the public apparently not. Now, in Antwerp, they are.

Wide scale mobilizations, including the dissemination of knowledge and giving this knowledge 'a stake' stimulated passion and debate, as a movement representative underscored:

Well, the popular referendum has played an incredibly dynamizing role in this. The idea was launched on the 20th of June. It was put into practice from the first week of September onwards, and seven months later we had 67.000 signatures [...] Because the intensity with which the public debate has been waged on this issue, the amount of communication that took place, the media pressure that has been created, but also the broad scope of media coverage, was of such a nature that, I think there was no city in the world where people knew more about particulate matter than Antwerp at that moment.

\footnotetext{
${ }^{3}$ The discussions were conducted in Dutch, which made it hard for some of the participants to express themselves. Sometimes translation was offered by fellow participants, and the practical assignments facilitated a degree of non-verbal communication, but still, a part of the participants appeared inhibited to fully express themselves.
} 
The movement developed various fora for this endeavor. On its websites, and through social and mainstream media strategies, information was widely shared. Both petitions brought volunteers out on the streets to collect signatures, providing opportunities to discuss the topic with thousands of people. Poster campaigns similarly spread the message of air pollution as a shared threat. More detailed information was disseminated in public and free 'Horta-seminars', held regularly at the centrally located Horta-café. These evenings were attended by $400-600$ people. During the Ringland campaign, even bigger crowds were gathered in similar seminars in a local theatre house and during a yearly Ringland festival. Finally, in collaboration with the University of Antwerp, two citizen science projects engaged thousands of residents to measure (and communicate) air pollution in front of their own house (Van Brussel \& Huyse, 2019).

In broad terms, the movement discourse consisted of two elements: first, connecting the ring road to the issue of air pollution and, second, a call for distributive justice, portraying Antwerp residents as victims of too much air pollution. Connecting the ring road and its extension plans to air pollution and its health risks has been crucial in staging air pollution as 'a matter of concern' (Kenis, 2020). Spatializing the discourse about traffic-related air pollution turned air pollution into a tangible object of contestation. The connection with the large-scale infrastructure project, which largely benefits people from outside the city and could still be resisted, gave the issue an unparalleled stake. The creation of well-delineated conflict lines stimulated passion in the debate and thereby contributed to raising considerable public interest for the topic (Kenis and Barratt, 2021; inspired by Mouffe, 2002; 2006). NOx decomposes relatively fast, and hence its concentration is markedly higher close to its source in comparison to PM, which dissipates over a large area. By making use of NOx, instead of PM maps, air pollution was visually connected with the ring road and traffic, and the (potential) impact of (new) infrastructure was plainly shown.

While NOx maps were instrumental in revealing the impact of the ring road and its planned extensions, PM , colloquially called 'fine dust' to make it more tangible, helped creating a movement identity around which all Antwerp residents could be mobilized. Using slogans like 'Fijn stof is slecht' ['Fine dust is bad'] and 'Leven in Antwerpen is ongezond' ['Living in Antwerp is unhealthy'], the movement emphasized the way in which (almost) the entire Antwerp population is affected by high levels of PM 2,5 and PM 10 and the related reduction of life expectancy. This latter discursive framing had a double effect. By disconnecting air pollution victimhood from its main source (the ring road) and pointing at the universally high levels of PM air pollution, the movement succeeded in appealing to all Antwerp residents, not just to those living closer to the ring road. Hence, they constructed Antwerp as a focus of victimhood which is shared, albeit to a lesser extent, with its surrounding municipalities and potentially the rest of the country. As a representative of the movement stated on reduced life expectancy: "On average, in Belgium, it's eight months, in Flanders ten months, and in Antwerp three years. That is unreasonably much in comparison with the average Belgian, and with the average Belgian it's already higher than in Europe, so it's utterly unreasonable." A policy maker summarised: "Yes, it's also about social justice. It's not because you live in Flanders that you have less right to clean air, compared to when you live in the middle of France". 
By presenting Antwerp residents as the apex of victimhood, the movement turned air pollution into a matter of indignation, contestation and debate inside Antwerp, without endangering (potential) alliances with movements in surrounding municipalities. Nonetheless, the scalar selectivity of the movement also had its blind spots. The focus on Antwerp to define victimhood, tended to conceal significant intra-urban variations in health risks. In particular, the social, ethnic and economic disparities underlying spatial exposure patterns remained largely underemphasized.

\subsection{Silenced inequalities}

Portraying the entire Antwerp population as a 'victim' of traffic related air pollution required silencing internal differences in exposure. Studies in Belgian cities have revealed how especially lower income and ethnic minority groups suffer higher levels of NO2 pollution (Loopmans et al., 2017; Smits, 2018; Verbeek, 2019). Given the higher vulnerability of poor and ethnic minority residents, their overexposure amounts to doubling injustice. In our interviews, the movement representatives emphasized that they are aware of this, that the movement aims to amend the situation, and that distributive justice is an important goal. At the same time, they conceptualize distributive justice as the result of a general improvement of the situation 'for all' and consider the active participation or awareness of the most affected populations as being of little relevance:

The [tunneling] of the ring road is good for everyone, especially for those living in these neighborhoods, and who mostly lives there? Migrants. So who has the biggest interest in establishing the [tunneling of] the ring? The migrants. (...). It's in their interest, whether they understand it themselves or not doesn't matter, because they breathe like everyone else. They benefit from every improvement.

The representatives underlined that they pleaded to first of all protect the most deprived areas from air pollution in their negotiations with the government, arguing that well-to-do areas don't need the movement to assure themselves of a healthy living environment: "We start with the most vulnerable neighborhoods. In 'Zuid' [a gentrified area] they will continue struggling and complaining to make sure they get their share too."

Nonetheless, the movement had so far not included these environmental injustices in their communication, and consciously so. When Movement X proposed to join the movement from an environmental racism perspective and to emphasize the socio-economically differentiated distance to the ring road, the movement organizers advised against using this frame, as it could put the movement's cohesion at risk ${ }^{4}$. Finding a balance between keeping the movement together and opening up spaces for politicization is a challenge for every social movement (Kenis and Mathijs, 2014; Kenis, 2021).

Unavoidably, every politicization inevitably entails a depoliticization. Yet, the choice to reject a discourse focusing on environmental racism is significant. Importantly, the relevance of distance to the ring road was recognized by movement representatives as such:

\footnotetext{
${ }^{4}$ To avoid misunderstandings, the movement did not resist Movement $X$ 's attempt to mobilize around this topic, but were hesitant to do so themselves for said reasons. However, shortly after, the Antwerp chapter of Movement $X$ disbanded and its EJ mobilization was aborted.
} 
The average citizen of Antwerp dies three years earlier as a consequence of this mess! Three years, on average! That means that for those who live within 300 meters of the ring road, it is probably four to five years! Well, that is significant, I would think?.

However, at the same time, no analysis was made, or at times even allowed about who is living closer to the ring road. Although a larger share of the non-white and poorer population of Antwerp is living in the most affected neighbourhoods, movement representatives portrayed these neighbourhoods as being mixed and explained that the white middle class residents of these neighbourhoods make up a large share of their active supporters. An analysis of the geographies of mobilization for the referendum indeed revealed how distance to the ring road is an important indicator for mobilization, but that the geographies of mobilization did not show correlations with patterns of socio-economic or ethnic segregation (Coppens et al, 2018). The analysis suggests that the movement's mobilization is mostly based on relatively segregated social networks of neighborhood based action groups, which, as has been explained above, are dominated by a white middle class constituency (Loopmans, 2010). Since the movement primarily focuses on the creation of political leverage and not so much on building intersectional cross class or cross race alliances, mobilizing these pre-existing networks of white middle class residents was considered the most cost-effective strategy, as a movement organizer explained: "We need to focus on the realization of political processes, in all senses of the word. Hence a public pedagogy of migrant groups is not our priority. We don't have excess energy, we are lacking energy." And another organizer emphasized:

We may reach tens of thousands of people, but in essence, this remains a very small organization. If we would focus more on diversity, and the participation of these groups, we should see how to organize our policy, and in the end that is about money.

Moreover, focusing on environmental racism or classism was feared to put off white middle class participants, and hence put the movement itself at risk. This does not mean that no effort at all was done to reach a broader audience, as this organizer emphasized:

We try to contact everyone's network. That contact, and then we ask to pass that on to that contact,... So that in the end, tens of neighborhood centers, mosques, have put up a 'CurieuzeNeuzen' poster in 2016, when we did the Antwerp citizen science project.

Though these efforts are relevant, the question remains to what extent these rather limited outreach activities bridge to poor or ethnic minority residents and enhance their capabilities to improve their health situation.

\subsection{Clearing the air: unequal access to knowledge and capabilities}

From a capabilities perspective on environmental justice, we could ask ourselves how the Antwerp air pollution movement could improve the capabilities of other citizens. Dissemination of environmental information, if not tailored to audiences with different socio-economic and ethnic backgrounds, results in differentiated learning. Given the movement's strategic emphasis on distributive justice and on mobilizing and informing white middle class residents, we could assume that poor and ethnic minority groups benefit the least (Cleary et al, 2017). In what follows, we analyze the capabilities of poorer urbanites with an 
ethnic minority background to deal with air pollution. On the basis of focus group discussions, we analyze whether our participants are reached by the air pollution movement, and whether they are aware and knowledgeable about air pollution and possible actions to improve their exposure and health. Our analysis suggests that the most exposed and most vulnerable groups lack crucial information to make informed decisions. Also, they perceive to have limited agency in relation to air pollution injustices, both at the individual and collective level.

To start with, only the participants of one focus group had heard of the Antwerp air pollution movement before. Most participants had clearly not been reached by the movement. Nonetheless, a limited amount of information on air pollution is acquired through media and social networks. As one participant notes: "My daughter tells me about it, and from television too." Additionally, participants claim to mostly base themselves upon their senses and their own experiences to distinguish pollution patterns in the city ("you can see that the windows of a building get black because of the dirty air"), as confirmed by other air pollution perception research (Burningham \& Thrush, 2003; Walker, 2012)

Most focus groups participants were aware of the important role played by traffic and industries as sources of air pollution in Antwerp, and rightfully considered Antwerp as more polluted than the surrounding suburbs and countryside. At a more detailed level however, perceptions of air quality did not always fit reality, which confirms the findings of other research (Bickerstaff \& Walker, 2001; Day, 2007, Kim et al., 2012). While at the same distance of the ring road, in neighborhoods outside the ring road, participants feel less exposed to air pollution than in the neighborhood inside. They seem to base their impression on the relatively quieter and cleaner environment in these areas. At Kiel, one woman had a particularly negative image of air quality in her neighborhood, but linked this to the presence, and the noise and buzz, of a football stadium in her street. Unless already suffering from air pollution related health conditions, participants rarely acknowledged their own vulnerability. As one participant said: "It might not be so healthy here, but that is mainly bad for the children, I don't have problems." Another participant added: "I think poor people have better immunity than rich. Because they already live with unhealthy food and in a house of lesser quality, that is more difficult."

Also, participants had a hard time imagining alternatives, and considered their own capabilities for individual or collective action restricted. Many participants agreed that leaving the polluted city center would improve their environmental living conditions, but emphasized that they do not have the means to realize it. As one participant mentioned: "Maybe it would be better to move, but it is very difficult. A house is very expensive, that is the problem." Someone else said: "I would rather live there, if I would have a car. (...) But now I will still live here for a while till I can go to work and have money for a car." Others emphasized racial discrimination as a reason not to move: "I will stay here, in Deurne. You know, there are fewer people like us in a village. Black I mean. That's not nice, people there aren't used to that, to people like me. I speak Dutch and so, but that is not enough over there. Here it is, here I am normal."

Throughout these interventions figured a strong sense of incapability to change their situation. As someone else noted: "I am suffering from migraine, I often take pills. I know the traffic is not good for me, but, you know, I have to live there." Even smaller lifestyle changes, like avoiding busy streets, were rarely considered realistic. Even if imagined, they were weighed against other priorities: "[Making a detour?] No, we don't have time for that. The shortest route is better." 
The fairness of the situation was discussed as well. Those who felt indignation about traffic-related air pollution, pointed to specific responsibilities and processes: "But why do they built [social housing] here if the air is so polluted? Why don't they built social housing in clean air, there are so many people living in social housing." someone else called out car-drivers: "I don't think it is fair. They come to pollute our air!" This differed markedly from the strategic communication by the movement, which avoided finger pointing car drivers as such. Similarly, the air quality difference between city and countryside was seen as unfair. At the same time, the current situation was naturalized in our participants discourses, leaving little room to imagine alternatives:

Far away from the city, the air quality is better, but they all come here with their car, that is the problem, that the air gets dirty here. [They come here] to work, to visit their lawyer, to go shopping. There is a lot here, and there are offices to work and so. Schools, physicians, universities etc. It's always busy in a city.

Whereas the movement contested the location and expansion of the ring road, amongst the focus group participants the location of infrastructure was considered unchangeable: "The ring road lies inside the city now, there is no road outside that they can take." Alternatives put forward by the movement were only known in the second focus group: "Ringland is the Ring road below the surface. (...) I think it would be good, cars can drive below the surface so there are none above the ground and so more parks can be constructed. The air quality will improve a lot."

The second focus group also stands out for their belief in collective action, and the potential of the movement to realize significant change. Other participants were rather hesitant or negative, suspicious about the unknown movement and the potential costs of supporting them. As a participant sharply summarized: "I don't assume they make a big difference, cause I have never heard of them and I live in Antwerp too." The suspicion of collective measures might also be fed by the participants' uniformly shared disagreement with the city's recently introduced low emission zone (LEZ), corresponding with criticisms in the literature claiming that the measure is socially unfair, as mainly lower income people are driving older, more polluting cars (Callens et al., 2013). As a participant noted:

I am no longer allowed to enter the city, unless I pay. But that is way too expensive, you have to pay each year and it gets more expensive too. So I had to get rid of my car. But the dirty air stays, because of the other people who do pay instead of abandoning their car.

The reactions to the LEZ illustrate how the participants are well aware of the capability inequalities they are facing when it comes to preventing or evading air pollution. Significantly, when the LEZ was introduced, the Antwerp air pollution movement hardly paid attention to it and remained ambivalent in their communication about it. The difference in indignation amongst the focus group participants with regard to air pollution on the one hand and the introduction of the LEZ on the other, also reveals the obscure nature of air quality. Antwerp's air pollution has mainly developed as the indirect consequence of infrastructural choices made at the political or business level as well as the result of the sum of a large number of small behavior choices, while the unjust effects of a LEZ can more directly be linked to a particular policy intervention. Similarly, in relation to the LEZ it seemed quite straightforward who is to blame, and who is victimized, while air pollution in general requires a wider knowledge base to 
conceptualize responsibilities and victimization. This might be linked to the failure of the movement to reach out to this group of residents.

\section{Conclusion}

Following the capabilities approach to environmental justice, as introduced by Schlosberg (2003) and Holland (2008), this paper showed that environmental justice is difficult to realize without equity in the distribution of networks, capabilities and knowledge. In other words, distributional justice cannot be separated from procedural dimensions, questions of recognition and capabilities (Walker, 2012). The largely invisible character of air pollution increases the importance of knowledge production and dissemination and therefore constitutes a core challenge for action groups and social movements. The particularity of air quality as an often intangible by-product of complex and seemingly unrelated decision procedures increases the importance of a pedagogical dimension to justice aims. Hence, equal access to knowledge and information are presented as important challenges for realizing procedural justice.

Social movements are important knowledge brokers and actively redistribute capabilities in society. The Antwerp movement fighting against the ring road has successfully put air pollution on the political agenda and has pursued a conscious and strategic educational program to produce and disseminate knowledge about air pollution in society, with the purpose of generating wider concern and support for its cause. As social movements have a big impact upon the distribution of knowledge and capabilities in society, it becomes relevant to analyze their own activities from an environmental justice perspective. Although clearly aiming for distributional justice in their proposals of alternatives to the ring road, and explicitly supportive of distributional equity in our interviews, the Antwerp movement organizers have strategically chosen to not voice such claims in their public communication or use them in their mobilizing efforts. They focused their knowledge dissemination efforts on those who, from the perspective of the movement leaders, are easier to mobilize by building upon the pre-existing, largely white middle class networks they were embedded in themselves. Restricting their communication to distributive justice at the city-scale, they evaded mobilizing around the specific situation of poorer and ethnic minority communities often living closer to the ring road. Consequently, they failed to enhance the capabilities of the most affected groups to develop their own strategies to protect themselves from air pollution. As suggested by our focus groups, the people who were not reached by the movements did not only have limited knowledge about the adverse effects of air pollution on their health, but also lacked the capabilities to imagine collective or even individual actions to improve their situation. The participants in our focus groups clearly held different priorities and a different understanding of responsibilities and strategies than the movement's messages conveyed, as is exemplified in the divergence in the reaction to the Antwerp LEZ. This suggest that simply extending communication networks will not suffice for the movement to become more inclusive. Shifting movement resources to more-than-distributive justice goals, would require a more intersectional approach which embraces solidarities with marginalized groups and re-examines movement priorities and strategies accordingly.

Finally, a capabilities approach to social movement organization sheds light on the pedagogical role of social movements. The specificity of traffic-related air pollution, as a particularly intangible and entangled 
environmental problem, contributed to uncovering the intricacies of movement pedagogies. Air pollution's need for visualization and explication pushes movements to embrace a public pedagogical role. This might be less explicit, but not less necessary in relation to other environmental issues. When movements restrict their focus to distributive justice, they might take up this pedagogical role in a restricted and sometimes even instrumentalist way, merely using it as a tool to mobilize activists and resources. However, when social movements embrace a wider capabilities approach, they would be able to see the potential of this public pedagogical role, and acknowledge that, in this way, they could not only affect policy making, but also societal change in a wider sense. 


\section{References}

Adey, P. (2013). Air/Atmospheres of the Megacity. Theory, Culture \& Society, 30(7/8), 291-308.

Amann, M., Bertok, I., Cabala, R., Cofala, J., Heyes, C., Gyarfas, F., ... \& Wagner, F. (2005). A final set of scenarios for the Clean Air For Europe (CAFE) programme (CAFE Scenario Analysis Report Nr.

6). International Institute for Applied Systems Analysis (IIASA).

Barnes, J. H., Chatterton, T. J., \& Longhurst, J. W. (2019). Emissions vs exposure: Increasing injustice from road traffic-related air pollution in the United Kingdom. Transportation research part D: transport and environment, 73, 56-66.

Beaumont, J., \& Loopmans, M. (2008). Towards radicalized communicative rationality: resident involvement and urban democracy in Rotterdam and Antwerp. International journal of urban and regional research, 32(1), 95-113.

Bickerstaff, K., \& Walker, G. (2001). Public understandings of air pollution: the 'localisation' of environmental risk. Global Environmental Change, 11, 133-145.

Bryant, R.L. (1998). Power, knowledge and political ecology in the third world: a review. Progress in Physical Geography, 22 (1), 79-94.

Burningham, K., \& Thrush, D. (2003). Experiencing environmental inequality: the everyday concerns of disadvantaged groups. Housing Studies, 18(4), 517-536.

Buzzelli, M. (2007). Bourdieu does environmental justice? Probing the linkages between population health and air pollution epidemiology. Health \& Place, 13, 3-13.

Buzzelli, M. (2008). A political ecology of scale in urban air pollution monitoring. Transactions of the Institute of British Geographers, 33(7), 502-517.

Callens, M., Noppe, J., \& Vanderleyden, L. (2013). De sociale staat van Vlaanderen 2013. Peer: Drukkerij Hendrix.

Claeys, M. (2013). Stilstand: over machtspolitiek, betweterbestuur en achterkamerdemocratie. Antwerp: Uitgeverij Van Halewyck.

Cleary, E. G., Patton, A. P., Wu, H. C., Xie, A., Stubblefield, J., Mass, W., \& Wong, C. (2017). Making air pollution visible: A tool for promoting environmental health literacy.JMIR public health and surveillance, $3(2)$, e16.

Collins, T.W., Grineski, S.E., Chakraborty, J., Montgomery, M.C., \& Hernandez, M. (2015). Downscaling environmental justice analysis: Determinants of household-level hazardous air pollutant exposure in greater houston. Annals of the Association of American Geographers, 105(4), 684-703.

Coppens, T., Van Dooren, W., \& Thijssen, P. (2018). Public opposition and the neighborhood effect: How social interaction explains protest against a large infrastructure project. Land use policy, 79, 633-640. 
Corburn, J. (2005). Street science: Community knowledge and environmental health justice. Boston: MIT Press.

Cupples, J. (2009). Culture, nature and particulate matter - Hybrid reframings in air pollution scholarship. Atmospheric Environment, 43, 207-217.

da Schio, N., Boussauw, K., \& Sansen, J. (2019). Accessibility versus air pollution: a geography of externalities in the Brussels agglomeration. Cities, 84, 178-189.

Davoudi, S., \& Brooks, E. (2014). When does unequal become unfair? Judging claims of environmental injustice. Environment and Planning A, 46, 2686-2702.

Day, R. (2007). Place and the experience of air quality. Health \& Place, 13(1), 249-260.

Delima, G., Jacobs, L., Loopmans, M., Ekyaligonza, M., Kabaseke, C., Kervyn, M., \& Mertens, K. (2021). DisCoord: Co-creating DRR knowledge in Uganda through interaction in a serious game. International Journal of Disaster Risk Reduction, 60, 102303.

Degraeuwe, B., Thunis, P., Clappier, A., Weiss, M., Lefebvre, W., Janssen, S., \& Vranckx, S. (2016). Impact of passenger car NOx emissions and NO2 fractions on urban NO2 pollution-Scenario analysis for the city of Antwerp, Belgium. Atmospheric Environment, 126, 218-224.

Fecht, D., Fisher, P., Fortunato, L., Hoek, G., de Hoogh, K., Marra, M., Kruize, H., Vienneau, D., Beelen, R., \& Hansell, A. (2015). Associations between air pollution and socioeconomic characteristics, ethnicity and age profile of neighbourhoods in England and the Netherlands. Environmental Pollution, 198, 201-210.

Fecht, D., Hansell, A. L., Morley, D., Dajnak, D., Vienneau, D., Beevers, S., ... \& Gulliver, J. (2016). Spatial and temporal associations of road traffic noise and air pollution in London: Implications for epidemiological studies. Environment international, 88, 235-242.

Finkelstein, R., \& Truchot, D. (2006). Le sentiment d'injustice dans la vie quotidienne: Introduction au numéro special « les théories de la justice et leurs applications ». Revue internationale de psychologie sociale, 19(1), 5-15.

Germani, A.R., Morone, P., \& Testa, G. (2014). Environmental justice and air pollution: a case study on Italian provinces. Ecological Economics, 106, 69-82.

Gibson-Wood, H., \& Wakefield, S. (2013). "Participation", white privilege and environmental justice: Understanding environmentalism among hispanics in Toronto. Antipode, 45(3), 641-662.

Gilbert, A., \& Chakraborty, J. (2011). Using geographically weighted regression for environmental justice analysis: Cumulative cancer risks from air toxics in Florida. Social Science Research, 40, 273-286.

Graham, S. (2015). Life support: The political ecology of urban air. City, 19(2/3), 192-215. 
Gray, S.C., Edwards, S.E., \& Miranda, M.L. (2013). Race, socioeconomic status, and air pollution exposure in North Carolina. Environmental Research, 126, 152-158.

Greenberg, M.R. (2005). Concern about environmental pollution: how much difference do race and ethnicity make? A New Jersey case study. Environmental Health Perspectives, 113(4), 369-374.

Guerra, E. (2015). The geography of car ownership in Mexico City: a joint model of households' residential location and car ownership decisions. Journal of Transport Geography, 43, 171-180.

Hajat, A., Hsia, C., \& O’Neill, M.S. (2015). Socioeconomic disparities and air pollution exposure: A global review. Current Environmental Health Reports, 2, 440-450.

Hamersma, M., Heinen, E., Tillema, T., \& Arts, J. (2015). Residential moving intentions at highway locations: The trade-off between nuisances and accessibility in the Netherlands. Transportation Research Part D, 35, 130-141.

Hamersma, M., Heinen, E., Tillema, T., \& Arts, J. (2017). The development of highway nuisance perception: Experiences of residents along the Southern Ring Road in Groningen, The Netherlands. Land Use Policy, 61, 553-563.

Holifield, R., Chakraborty, J., \& Walker, G. (2017). The Routledge Handbook of Environmental Justice. Londen: Routledge.

Holland, B. (2008). Ecology and the limits of justice: Establishing capability ceilings in Nussbaum's capabilities approach. Journal of Human Development, 9(3), 401-425.

Kashwan, P. (2017). Inequality, democracy, and the environment: a cross-national analysis. Ecological Economics, 131, 139-151.

Kenis, A. (2021). Clashing Tactics, Clashing Generations: The Politics of the School Strikes for Climate in Belgium. Politics And Governance, 9 (2), 135-145. doi: 10.17645/pag.v9i2.3869.

Kenis A., Barratt B. (2021). The role of the media in staging air pollution: The controversy on extreme air pollution along Oxford Street and other debates on poor air quality in London. Environment and Planning C: Politics and Space. doi: 10.1177/2399654420981607.

Kenis, A., Lievens, M. (2020). Politicizing air: on the political effects of spatial imagination. In: F. Landau, L. Pohl, N. Roskamm (Eds.), [Un]Grounding. Post-Foundational Geographies. London: Transcript, pp. 261-278.

Kenis A., Mathijs E. (2014). Climate change and post-politics: repoliticising the present by imagining the future? Geoforum, 52, 148-156.

Kim, M., Yi, O., \& Kim, H. (2012). The role of differences in individual and community attributes in perceived air quality. Science of the Total Environment, 425, 20-26. 
Knibbs, L.D., \& Barnett, A.G. (2015). Assessing environmental inequalities in ambient air pollution across urban Australia. Spatial and Spatio-temporal Epidemiology, 13, 1-6.

Kojola, E., \& Pellow, D. N. (2020). New directions in environmental justice studies: examining the state and violence. Environmental Politics, 1-19.

Khomenko, S., Cirach, M., Pereira-Barboza, E., Mueller, N., Barrera-Gómez, J., Rojas-Rueda, D., ... \& Nieuwenhuijsen, M. (2021). Premature mortality due to air pollution in European cities: $A$ health impact assessment. The Lancet Planetary Health. https://doi.org/10.1016/S2542-5196(20)30272-2

Laurian, L. \& Funderburg, R. (2014) Environmental justice in France? A spatio-temporal analysis of incinerator location. Journal of Environmental Planning and Management, 57:3, 424-446.

Lefebvre, W., Schillemans, L., Op't Eyndt, T., Vandersickel, M., Poncelet, P., Neuteleers, C., ... \& Mayeres, I. (2011). Voorstel van maatregelen om de luchtkwaliteit te verbeteren en de geluidshinder te beheersen in de stad Antwerpen. VITO: unpublished report.

Lejeune, Z., \& Teller, J. (2016). Incentives and barriers to environmental inequality mobilization: A casestudy analysis in Wallonia, Belgium. Environmental Science \& Policy, 66, 208-216.

Loopmans, M. (2008). Relevance, gentrification and the development of a new hegemony on urban policies in Antwerp, Belgium. Urban Studies, 45(12), 2499-2519.

Loopmans, M. (2010). Threatened or empowered? The impact of neighborhood context on community involvement in Antwerp, Belgium. Urban affairs review, 45(6), 797-820.

Loopmans, M. (2014) David tegen Lange Wapper (David Against Lange Wapper), Agora, 30(3), 16-19.

Loopmans, M., Marrécau, F., Kenis, A. (2017). Louter lucht? Lucht, ongelijkheid en sociaal protest. Agora. Magazine voor sociaalruimtelijke vraagstukken, 2, $18-21$.

Loopmans, M., Brown, G., \& De Craene, V. (2020). Everyday Spatialities of Intersectional Solidarity and Activism. Tijdschrift voor economische en sociale geografie. 112(2), 101-106.

Maantay, J. (2007). Asthma and air pollution in the Bronx: methodological and data considerations in using GIS for environmental justice and health research. Health \& Place, 13, 32-56.

Maiheu, B., Vranckx, S, Lefebvre, W. \& S. Janssen (2015) Luchtkwaliteitsmodellering Ringland, VITO: Mol, https://content.ringland.be/studies/Luchtkwaliteitsmodellering-Ringland-VITO.pdf

Makri, A., \& Stilianakis, N.I. (2008). Vulnerability to air pollution health effects. International Journal of Hygiene and Environmental Health, 211, 326-336.

Maroko, A. R. (2012). Using air dispersion modeling and proximity analysis to assess chronic exposure to fine particulate matter and environmental justice in New York City. Applied Geography, 34, 533-547.

Mitchell, G., \& Dorling, D. (2003). An environmental justice analysis of British air quality. Environment and Planning A, 35, 909-929. 
Mouffe, C. (2002). Politics and passions. The stakes of democracy. London: CSD Perspectives.

Mouffe, C. (2006). On the political. London: Routledge.

Mukherjee, B.N. (1993). Public response to air pollution in Calcutta Proper. Journal of Environmental Psychology, 13, 207-230.

Nyarku, M., Mazaheri, M., Jayaratne, R., Dunbabin, M., Rahman, M. M., Uhde, E., \& Morawska, L. (2018). Mobile phones as monitors of personal exposure to air pollution: Is this the future?. PloS one, 13(2), e0193150.

Pearce, J.R., Richardson, E.A., Mitchell, R.J., \& Shortt, N.K. (2010). Environmental justice and health: the implications of the socio-spatial distribution of multiple environmental deprivation for health inequalities in the United Kingdom. Transactions of the Institute of British Geographers, 35(4), 522539.

Peng, M., Zhang, H., Evans, R. D., Zhong, X., \& Yang, K. (2019). Actual air pollution, environmental transparency, and the perception of air pollution in China. The Journal of Environment \& Development, 28(1), 78-105.

Pezzullo, P. C. (2001). Performing critical interruptions: Stories, rhetorical invention, and the environmental justice movement. Western Journal of Communication (includes Communication Reports), 65(1), 1-25.

Pulido, L. (1996). Environmentalism and economic justice: Two Chicano struggles in the Southwest. University of Arizona Press.

Robeyns, I. (2003). Is Nancy Fraser's critique of theories of distributive justice justified?. Constellations, 10(4), 538-554.

Rose-Pérez, R. (2015). Environmental justice and air quality in Santiago de Chile. Revista de Salud Pública, 17(3), 337-350.

Samenlevingsopbouw Antwerpen stad (2017). Taal*Oor: samen praten. Consulted online on 29/07/2019 via https://samenlevingsopbouw-antwerpenstad.be/wat-doen-we/activiteit/taaloor

Schlosberg, D. (2003). The justice of environmental justice: reconciling equity, recognition, and participation in a political movement. Moral and political reasoning in environmental practice, 77, 106.

Schlosberg D (2007) Defining Environmental Justice: Theories, Movements and Nature. Oxford: Oxford University Press.

Schlosberg, D. (2013). Theorising environmental justice: the expanding sphere of a discourse. Environmental politics, 22(1), 37-55.

Schlosberg, D., \& Carruthers, D. (2010). Indigenous struggles, environmental justice, and community capabilities. Global Environmental Politics, 10(4), 12-35. 
Smits, L. (2018) Luchtvervuiling in Antwerpen: een kwantitatief en kwalitatief onderzoek naar milieuonrechtvaardigheid. Unpublished master thesis, Leuven: KULeuven.

Sze, J. (2006). Noxious New York: The racial politics of urban health and environmental justice. Boston: MIT press.

Sze, J., \& London, J. K. (2008). Environmental justice at the crossroads. Sociology Compass, 2(4), 13311354.

Taylor, D. Taylor, D. (2014). Toxic communities: Environmental racism, industrial pollution, and residential mobility. NYU Press.

Tenailleau, Q.M., Mauny, F., Joly, D., Francois, S., \& Bernard, N. (2015). Air pollution in moderately polluted urban areas: How does the definition of "neighborhood" impact exposure assessment? Environmental Pollution, 206, 437-448.

Van Brussel, S., \& Huyse, H. (2019). Citizen science on speed? Realizing the triple objective of scientific rigour, policy influence and deep citizen engagement in a large-scale citizen science project on ambient air quality in Antwerp. Journal of Environmental Planning and Management, 62(3), 534-551.

Van Brusselen, D., Arrozola de Õnate, W., Maiheu, B., Vranckx, S., Lefebvre, W., Janssen, S., Nawrot, T.S., Nemery, B., \& Avonts, D. (2016). Health impact assessment of a predicted air quality change by moving traffic from an urban ring road into a tunnel. The case of Antwerp, Belgium. PLOS ONE, 11(5), 1-19.

Véron, R. (2006). Remaking urban environments: the political ecology of air pollution in Delhi. Environment and Planning A, 38, 2093-2109.

VMM (2020a) Verloren gezonde levensjaren (DALY's) door fijn stof, https://www.milieurapport.be/milieuthemas/milieu-gezondheid/dalys/verloren-gezonde-levensjarendalys-door-blootstelling-aan-fijn-stof, last visit 18/03/2021

VMM (2020b) Milieurapport: transport, https://www.milieurapport.be/sectoren/transport, last visit $18 / 03 / 2021$

VMM (2020c) Jaarrapport Lucht : Emissies en concentraties van luchtverontreinigende stoffen, https://www.vlaanderen.be/publicaties/jaarrapport-lucht-emissies-en-concentraties-vanluchtverontreinigende-stoffen, last visit 18/03/2021

Wakefield, S., Elliott, S.J., Eyles, J.D., \& Cole, D.C. (2006). Taking environmental action: the role of local composition, context, and collective. Environmental Management, 37(1), 40-53.

Verbeek, T. (2019). Unequal residential exposure to air pollution and noise: A geospatial environmental justice analysis for Ghent, Belgium. SSM-population health, 7, 100340.

Véron, R. (2006). Remaking urban environments: the political ecology of air pollution in Delhi. Environment and Planning A, 38(11), 2093-2109. 
Walker, G. (2009). Beyond distribution and proximity: exploring the multiple spatialities of environmental justice. Antipode, 41(4), 614-636.

Walker, G. (2012). Environmental justice: concepts, evidence and politics. London: Routledge.

Walker, M. (2006). Towards a capability-based theory of social justice for education policy-making. Journal of Education Policy, 21(2), 163-185.

Whitehead, M. (2009). State, Science and the Skies: Governmentalities of the British atmosphere. Oxford: John Wiley \& Sons

Wolf, E. E. A., \& Van Dooren, W. (2017). How policies become contested: A spiral of imagination and evidence in a large infrastructure project. Policy sciences, 50(3), 449-468. 